DOI: 10.12731/2227-930X-2021-11-4-53-66 УДК 656.025

\title{
РАЗВИТИЕ ТРАНСПОРТНОЙ СИСТЕМЫ ЧЕРЕЗ СОЗДАНИЕ РЕГИОНАЛЬНОГО ТРАНСПОРТНО-ЛОГИСТИЧЕСКОГО КЛАСТЕРА
}

\section{Миркина О.Н.}

Транспортная система является важной отраслью экономики страны. Направление и иели ее развития определяется государством, которое разрабатывает Транспортную стратегию. Действующая Транспортная стратегия определяет необходимость увеличения объема и скорости транзита грузов и развитие мультимодальных логистических технологий. Bbявлено замедление развития транспортной отрасли России. Стимулом к ее развитию может быть создание мультимодальных транспортно-логистических иентров федерального, регионального и территориального уровня. Формой реализации таких центров могут быть транспортно-логистические кластеры. На территории Смоленской области можно организовать один из таких иентров регионального уровня - создать транспортно-логистический кластер. Это окажет положительное влияние на транспортную систему, экономику региона и страны.

Цель-рассмотрение путей развития транспортной системь путем создания транспортно-логистического кластера на территории региона.

Метод или методология проведения работы: в исследовании применялись системный подход и общенаучные методы - статистический, сравнительный анализ, экспертные оценки и логические обобщения.

Результаты: показана возможность создавать транспортно-логистические иеетры на примере региона. 
Область применения результатов: полученные результаты иелесообразно применять региональным властям, экономическим субъектам, осуществляющими инвестиционную деятельность 8 сфере трансопртра и логистики.

Ключевые слова: транспортная система; транспортно-логистические центры; транспортно-логистические кластеры; Смоленская область

\section{DEVELOPMENT OF THE TRANSPORT SYSTEM THROUGH THE CREATION OF A REGIONAL TRANSPORT AND LOGISTICS CLUSTER}

\section{Mirkina O.N.}

The transport system is an important branch of the country's economy. The direction and objectives of its development are determined by the state that is developing the Transport Strategy. The current Transport Strategy determines the need to increase the volume and speed of transit of goods and the development of multimodal logistics technologies. A slowdown in the development of the transport industry in Russia has been revealed. The stimulus for its development may be the creation of multimodal transport and logistics centers at the federal, regional and territorial levels. Transport and logistics clusters can be a form of implementation of such centers. On the territory of the Smolensk region, one of these centers of the regional level can be organized - to create a transport and logistics cluster. This will have a positive impact on the transport system, the economy of the region and the country.

The goal is to consider ways to develop the transport system by creating a transport and logistics cluster in the region.

Method or methodology of work: the study used a systematic approach and general scientific methods - statistical, comparative analysis, expert assessments and logical generalizations.

Results - Shows how to create transportation and logistics centers using the example of a region. 
The scope of the results: it is advisable to apply the results to regional authorities, economic entities engaged in investment activities in the field of transport and logistics.

Keywords: transport system; transport and logistics centers; transport and logistics clusters; Smolensk region

Транспортная отрасль в экономике России играет едва ли не ключевую роль, поскольку позволяет перемещать грузы и пассажиров, создавая единое экономическое пространство внутри страны и связывая ее с внешним миром.

Значение транспортной отрасли для экономики страны велико, именно поэтому государство считает необходимым осуществление определенного ее регулирования. В частности в России принимается и реализуется Транспортная стратегия [9], где оговаривается государственная политика в данной отрасли на долгосрочный период, цели развития транспортной системы, особенности применения стратегии в отношении всех видов транспорта. Стратегия подчеркивает, что «миссия государства в сфере обеспечения функционирования и развития транспортной системы заключается в создании условий для повышения качества жизни и здоровья граждан, экономического роста и повышения конкурентоспособности национальной экономики, укрепления безопасности и обороноспособности страны, реализации ее транспортного потенциала через опережающее развитие транспортной инфраструктуры и расширение доступа к безопасным и качественным транспортным услугам с минимальным воздействием на окружающую среду и климат, использование географических особенностей Российской Федерации в качестве ее конкурентного преимущества» [9].

Стратегия предусматривает реализацию следующих долгосрочных целей развития транспортной системы, под которой понимается система, объединяющая объекты, субъекты и средства транспортного комплекса при помощи технологий осуществления перевозок и управления ими, а также заданных нормативно-правовых условий их функционирования: 
- повышение пространственной связанности и транспортной доступности территорий;

- повышение мобильности населения и развитие внутреннего туризма;

- увеличение объема и скорости транзита грузов и развитие мультимодальных логистических технологий;

- цифровая и низкоуглеродная трансформация отрасли и ускоренное внедрение новых технологий.

Транспортная стратегия предполагает формирование единого транспортного пространства Российской Федерации на базе сбалансированного развития эффективной транспортной инфраструктуры. В процессе реализации необходимо объединить в единую сеть транспортные коммуникации, технологическую инфраструктуру и грузовладельцев, ввести единые стандарты информационной среды и технологического взаимодействия. В рамках формирования единого транспортного пространства предусматривается комплексное развитие транспортных систем Сибири, Урала, Дальнего Востока, Северо-Запада, Центра, Юга России, Поволжья, прежде всего на направлениях основных транспортных коридоров [1].

Оценить состояние транспортной системы России можно на основе данных статистики. На долю отрасли «Транспортировка и хранение» в 2020 г. приходится 6,5\% валовой добавленной стоимости, наблюдается некоторое ее снижение по сравнению с показателем 2018 г. (6,6\%). Увеличивается численность занятых в отрасли - в 2020 г. она составила 5493,0 тыс. чел. (7,93\% среднегодовой численности занятых по России) против 5353, 1 тыс. чел. (7,48\%) в 2018 г. Характеризуя объемы деятельности транспортной отрасли, можно сказать, что перевозки грузов всеми видами транспорта в 2020 г. составили 7846 млн тонн, что на 5\% меньше, чем в 2018 г. Больше всего грузов перевезено автомобильным транспортом (69\% в 2020 г.). Грузооборот в рассматриваемом периоде также снижается: с 5635 млрд тонно-километров в 2018 г. до 5401 млрд тонно-километров в 2020 г. Наибольшие объемы грузооборота приходятся на железнодорожный и трубопроводный 
транспорт. Протяженность путей сообщения за рассматриваемый период изменилась незначительно. Стоит отметить, что в рассматриваемом периоде несколько снизилась степень износа основных фондов (с 55,7\% в 2018 г. до 53,9\% в 2020 г.), это связано, скорее всего, с введением в эксплуатацию объектов основных фондов отрасли «Транспортировка и хранение». Таким образом, доля транспортной отрасли в валовой добавленной стоимости России довольно невелика, снижаются абсолютные показатели деятельности отрасли в течение рассматриваемого периода, но одним из факторов, объясняющих такую ситуацию, является, безусловно, ряд ограничений, вызванных ограничениями в связи с пандемией короновирусной инфекции COVID-19. В пользу развития отрасли говорит рост численности занятых в ней и некоторое обновление основных фондов.

Современная транспортная система не будет эффективной без транспортно-логистических центров, которые направлены на обеспечение ускоренной обработки грузов, снижению затрат на их доставку, и направлены, в первую очередь, на реализацию экспортного и транзитного потенциала России [4].

В научной литературе используется понятие мультимодальные транспортно-логистические центры (МТЛЦ) [8]. Речь о них идет в контексте логистической инфраструктуры международного транспортного коридора как о ее основополагающих элементах. Предполагается, что МТЛЦ функционируют на коммерческой основе, обеспечивают скоординированное взаимодействие всех видов транспорта и других участников транспортно-логистического процесса. Они также рассматриваются как стратегические точки роста экономики России.

Создание таких центров является перспективным, поскольку Россия является частью мировой экономики, а по оценке экспертов, в первой четверти XXI века в крупнейших транспортных узлах мира будет создано порядка 60-70 МТЛЦ международного уровня, которые будут связаны между собой интермодальными транспортными коридорами с подключением к ним региональных 
логистических систем, обеспечивающих выход к каждому грузоотправителю и грузополучателю. Такая схема организации доставки грузов экономически оправдана - она обеспечит повышение эффективности транспортно-распределительного процесса более чем на $30-40 \%$ [8].

Россия должна включиться в этот процесс. По оценкам экспертов, в первой четверти XXI века на территории России потребуется сформировать, по предварительной оценке, 10 МТЛЦ федерального уровня, порядка 20 МТЛЦ - регионального уровня и свыше 50 МТЛЦ территориального ранга [8].

Крупными мультимодальными узлами федерального уровня признаются Московский, Ленинградский, Новосибирский, Горьковский, Калининградский, Краснодарский, Свердловский, Красноярский, Иркутский и Хабаровский транспортные узлы, тяготеющие к международным и национальным транспортным коридорам. Они выступают узловыми точками общероссийской сети МТЛЦ. Для их функционирования целесообразно создание опорной сети региональных терминалов и логистических центров, объединенных в региональные транспортно-логистические системы. Целостность таким системам придадут единые организационно-экономическое, информационное, научно-техническое, кадровое и нормативно-правовое обеспечение управления системой грузо- и товародвижения.

Смоленская область, обладая уникальным географическим положением, рассматривается как один из возможных центров размещения МТЛЦ регионального уровня. Создание такого центра позволило бы региону получить конкурентные преимущества в борьбе за инвестиционные ресурсы, стало бы стимулом к его развитию.

О целесообразности размещения в Смоленской области МТЛЦ можно судить опираясь на следующие данные. Область занимает выгодное геополитическое положение, способствующее развитию межрегионального сотрудничества и сотрудничества с ближним зарубежьем. Транспортная система Смоленской области представлена железнодорожным, автомобильным, трубопроводным транспортом и соответствующей инфраструктурой [2]. 
Смоленская область включает два международных транспортных коридора, которые играют ведущую роль в формировании интегрированного глобального рынка транспортных услуг [7]. По территории области пролегает часть Панъевропейского транспортного коридора, который связывает с востока на запад Центральную Россию с государствами Европейского союза. Он представлен железнодорожной и автомобильной магистралями Москва - Минск Варшава - Берлин. В южном направлении регион пересекается транспортным коридором «Север-Юг». В настоящее время ведутся работы по расширению его инфраструктуры.

Опираясь на данные статистики, можно охарактеризовать состояние транспортной системы региона. На долю отрасли «Транспортировка и хранение» в 2019 г. пришлось 10,3\% валовой добавленной стоимости, против 9,7\% в 2018 г., незначительно увеличился индекс физического объема валовой добавленной стоимости по сравнению с показателем 2018 г. на 2,8\% [6].

Сопоставимая доля отрасли «Транспортировка и хранение» в среднегодовой численности занятых региона составляет 9,6\% в 2019 г. Наблюдается незначительное увеличение среднегодовой численности занятых по сравнению с 2018 г. - на 0,6 тыс. чел. (+1,5\%).

Рассматривая данные деятельности транспорта региона можно отметить, что эксплуатационная длина железнодорожных путей сообщения общего пользования на конец 2019 г. составила 1123 км, что на 33 км меньше, чем в периоде 2015-2018 гг. Эксплуатационная длина автомобильных дорог с твердым покрытием (включая дороги необщего пользования) в 2019 г. составила 16183 км, т.е. увеличилась на 12,5\% против показателя в 2015 г.

Смоленская область располагает обширной транспортной инфраструктурой. Удельный вес основных фондов отрасли «Транспортировка и хранение» в основных фондах региона составил в 2019 г. - 28,9\% (307622 млн. руб. в 2019 г. против 307694 млн. руб. в 2018 г.). Незначительно возросла степень износа основных фондов - с 57,4\% в 2018 г. до 59,8\% в 2019 г., соответственно снизился коэффициент обновления основных фондов - с 4,8\% до 4,2\%. Это 
говорит о высокой степени износа основных фондов рассматриваемой отрасли. Стоит отметить снижение абсолютной величины стоимости ввода в действие основных фондов отрасли «Транспортировка и хранение»: если в 2018 г. ввели основных фондов на сумму 14638 млн руб., то в 2019 г. - 13027 млн руб. или на $11 \%$ меньше. Инвестиции в отрасль составили в 2018 г. составили 11420,5 млн руб. (24\% от общего объема инвестиций в основной капитал региона), в 2019 г. отмечен рост этого показателя до 13400,8 млн руб. Однако в 2020 г. произошло резкое снижение 10050,1 млн руб., что на 12\% меньше объема инвестиций 2018 г.

Таким образом, Смоленская область своим приграничным расположением объективно является «воротами» для грузовых и пассажирских потоков. Это делает необходимым развитие на ее территории субъектов транспортной и логистической инфраструктуры. О том, что регион располагает для этого определенной материальной базой свидетельствует тот факт, что почти треть среднегодовой стоимости основных фондов приходится на отрасль «Транспортировка и хранение». Стоит признать, что доля этой отрасли в валовой добавленной стоимости региона и численность занятых в ней невелики. Однако при достаточном уровне финансирования в регионе можно развивать транспортно-логистическое направление.

МТЛЦ в регионе может быть в форме транспортно-логистического кластера. Кластер представляет собой формы территориально-отраслевой организации производства, способствующей реализации инновационных предпринимательских проектов экономического развития, обусловливающих синергетический эффект взаимодействия. Территориальная близость рассматривается как место накопления «критической массы» человеческого капитала, научного, инновационного и производственного потенциалов [1].

Власти Смоленской области поддерживают создание и развитие кластеров на территории региона. В частности формируются туристский, льняной, информационных технологий и композит- 
ный кластеры [5]. Однако транспортно-логистическое направление в настоящее время поддержки не получило.

В пользу формирования на территории Смоленской области транспортно-логистического кластера можно перечислить следующие факторы:

1. выгодное экономико-географическое положение региона;

2. сложившаяся транспортно-логистическая инфраструктура, включая 3 автомобильных дороги федерального значения, 6 таможенно-логистических терминалов, 3 транспортных узла и т.д.;

3. наличие региональных целевых программ, направленных на развитие транспортного комплекса;

4. реализация значимых инвестиционных проектов в регионе: «Строительство логистического комплекса» ГК «Транском» (Вяземский район), «Строительство транспортно-логистического центра» $\mathrm{OOO}$ «Ред Стар» (Кардымовский район), «Строительство складского комплекса» ООО «Терминал Никольский» (Смоленский район);

5. развитая система обучения и повышения квалификации кадров и т.д.

Однако существует ряд проблем сдерживающих эффективное развитие транспортной отрасли и формирование транспортно-логистического кластера:

- недостаточный уровень развития в Смоленской области транспортной инфраструктуры, высокий износ отдельных ее объектов и несоответствие современным требованиям;

- вследствие ряда причин, в том числе финансовых, невосприимчивость региональных предприятий к инновациям в развитии парка подвижного состава, современных автоматизированных систем контроля и учета внутренних перевозок;

- диспропорции в темпах и масштабах развития различных видов транспорта, нестабильности рынка, возникшей под воздействием санкций, нехватки квалифицированных трудовых ресурсов, несовершенных мерах регулирования со стороны государства. 
В связи с этим оказывается целесообразным развитие транспортной системы Смоленской области путем создания транспортно-логистического кластера.

Кластеры в транспортной системе должны быть высокопроизводительными и ориентированными на крупномасштабные транзитные грузовые перевозки, для чего требуются структуры, использующие новые эффективные технологии, применяющие новые виды материалов и транспортных средств [1].

Для создания транспортно-логистического кластера Смоленской области можно использовать алгоритм, который предполагает последовательное выполнение шести этапов:

1. опираясь на ряд исследований, в том числе расчет и анализ отраслевых коэффициентов, мнения экспертов, оценка возможности формирования и развития транспортно-логистического кластера;

2. применяя системный и процессный подходы выявление существующих и недостающих элементов транспортно-логистического кластера;

3. оценка наличия и эффективности взаимосвязей, возникающих внутри кластера;

4. учитывающей особенности региона, отраслей и потенциальных участников комплекса, взаимодействие с властями разработка стратегии развития транспортно-логистического кластера;

5. формирование организационной и функциональной структуры транспортно-логистического кластера;

6. на основе показателей деятельности отдельных предприятий, входящих в состав кластера, региона в целом оценка потенциальных эффектов создания транспортно-логистического кластера.

Создание транспортно-логистического кластера положительно скажется на транспортной системе региона. Привлечение дополнительных инвестиций позволит обновить и расширить объекты дорожной инфраструктуры, создать дополнительные логистические мощности, позволит реализовать инновационные мероприятия с целью повышения эффективности транспортной системы. 
Создание в Смоленской области транспортно-логистического кластера имеет ряд положительных последствий как для самого региона, так и для страны в целом. Для области они выражаются в расширении производственной базы, создании дополнительных рабочих мест. К положительным результатам можно также отнести развитие сопутствующих видов экономической деятельности; оптимизацию использования земельного фонда в регионе; увеличение налогооблагаемой базы и повышение инвестиционной привлекательности региона [3]. Для страны в целом положительный эффект выражается, прежде всего, в ускорении транспортировки и обработки грузов, расширении участия страны в международных транспортных потоках, увеличение налоговых поступлений.

Таким образом, транспортная отрасль является одной из важнейших отраслей экономики. В России реализуется Транспортная стратегия, определяющая направления развития транспортной и сопутствующих отраслей на период до 2030 г. Включенность России в международное товародвижение проявляется в создании на ее территории международных транспортных коридоров, некоторые из которых проходят в частности по территории Смоленской области. Представляется целесообразным использование этой особенности для развития транспортной системы региона через создание в Смоленской области мультимодального транспортно-логистического центра регионального уровня в форме транспортно-логистического кластера. Это позволит привлечь инвестиции в транспортную отрасль региона, обновить и расширить транспортную и логистическую инфраструктуру, будет также положительный социальный и экономический эффект для региона и страны в целом.

\section{Список литературы}

1. Жовтун Д.Т. Кластерный анализ транспортных систем России // Транспортное право и безопасность. 2017. № 2(14). С. 55-58.

2. Катровский А.П. Транспортная связность и туристское освоение Российско-Белорусского приграничья // Материалы XXIII Между- 
народной научно-практической конференции «Наука - сервису». Москва, 10 октября 2018 года. Под редакцией И.В. Бушуевой, О.Е. Афанасьева. М.: Издательство: РУСАЙНС, 2018. С. 57-65.

3. Ковшикова Г. А., Кошелева А. В. Создание транспортно-логистического центракак фактор активизации торговых отношений в регионе // Логистические системы в глобальной экономике: материалы Междунар. науч.-практ. конф. (30-31 марта 2020 г., Красноярск) / Сиб. гос.аэрокосмич. ун-т. Красноярск, 2020. С. 156-161.

4. Мамедзаде, Х. М. Развитие транспортных систем как часть государственной экономической политики России / Х. М. Мамедзаде, А. А. Молотиевская, О. И. Гассиева // Современная экономика: актуальные вопросы, достижения и инновации: сборник статей XXXIII Международной научно-практической конференции: в 2 ч., Пенза, 20 декабря 2019 года. Пенза: «Наука и Просвещение» (ИП Гуляев Г.Ю.), 2019. С. 191-193.

5. Миркина О.Н. Оценка формирования промышленных кластеров Смоленской области // Региональные проблемы преобразования экономики. 2020. № 12(122). С. 7-13. https://doi.org/10.26726/18127096-2020-12-7-13

6. Миркина О.Н. Оценка транспортной системы Смоленской области // Наука Красноярья. 2021. Т. 10, № 1-3. С. 99-103.

7. Научные основы создания и функционирования международных транспортных коридоров на территории России / С. С. Титова, В. М. Макурина, А. И. Карпова, А. В. Смольянинов // International Journal of Advanced Studies. 2021. T. 11, № 2. C. 21-35. https://doi. org/10.12731/2227-930X-2021-11-2-21-35

8. Прокофьева Т.А. Развитие логистической инфраструктуры как стратегическое направление интеграции России в систему международных транспортных коридоров // В центре экономики. 2021. № 1. С. 1-10.

9. Распоряжение Правительства РФ от 27 ноября 2021 г. № 3363-р «О Транспортной стратегии Российской Федерации до 2030 года с прогнозом на период до 2035 года». https://www.garant.ru/products/ ipo/prime/doc/403056321/ 


\section{References}

1. Zhovtun D.T. Transportnoe pravo i bezopasnost', 2017, no. № 2(14), pp. 55-58.

2. Katrovskiy A.P. Materialy KhXIII Mezhdunarodnoy nauchno-prakticheskoy konferentsii «Nauka - servisu». Moskva, 10 oktyabrya 2018 goda [Proceedings of the XXIII International Scientific and Practical Conference "Science for Service". Moscow, October 10, 2018]. Edited by I.V. Bushueva, O.E. Afanasiev. M.: Izdatel'stvo: RUSAYNS, 2018, pp. 57-65.

3. Kovshikova G.A., Kosheleva A.V. Logisticheskie sistemy v global'noy ekonomike: materialy Mezhdunar. nauch.-prakt. konf. (30-31 marta 2020 g., Krasnoyarsk [Logistic systems in the global economy: materials of the Intern. scientific-practical. conf. (March 30-31, 2020, Krasnoyarsk)]. Krasnoyarsk, 2020, pp. 156-161.

4. Mamedzade Kh.M., Molotievskaya A.A., Gassieva O.I. Sovremennaya ekonomika: aktual'nye voprosy, dostizheniya i innovatsii: sbornik statey XXXIII Mezhdunarodnoy nauchno-prakticheskoy konferentsii: $v 2$ ch., Penza, 20 dekabrya 2019 goda [Modern economy: topical issues, achievements and innovations: collection of articles XXXIII International Scientific and Practical Conference: at 2 pm, Penza, December 20, 2019]. Penza: "Nauka i Prosveshchenie" (IP Gulyaev G.Yu.), 2019, pp. 191-193.

5. Mirkina O.N. Regional'nye problemy preobrazovaniya ekonomiki, 2020, no. 12(122), pp. 7-13. https://doi.org/10.26726/1812-7096-202012-7-13

6. Mirkina O.N. Nauka Krasnoyar'ya, 2021, vol. 10, no. 1-3, pp. 99-103.

7. Titova S.S., Makurina V.M., Karpova A.I., Smol'yaninov A.V. International Journal of Advanced Studies, 2021, vol. 11, no. 2, pp. 21-35. https://doi.org/10.12731/2227-930X-2021-11-2-21-35

8. Prokof'eva T.A. V tsentre ekonomiki, 2021, no. 1, pp. 1-10.

9. Decree of the Government of the Russian Federation of November 27, 2021 No. 3363-r "On the Transport Strategy of the Russian Federation until 2030 with a forecast for the period up to 2035". https://www.garant.ru/products/ipo/prime/doc/403056321/ 


\section{ДАННЫЕ ОБ АВТОРЕ}

Миркина Ольга Наумовна, доцент кафедры экономики, кандидат экономических наук, доцент

Смоленский государственный университет

ул. Пржевальского, 4, г. Смоленск, 214000, Российская Федераичи

olga-mirkina@yandex.ru

\section{DATA ABOUT THE AUTHOR}

Olga N. Mirkina, Associate Professor of Economics, Candidate of Economics

Smolensk state University

4, Przewalski Str., Smolensk, 214000, Russian Federation

olga-mirkina@yandex.ru

SPIN-code: 5972-7929

ORCID: 0000-0001-8040-8353

Поступила 27.10.2021

Received 27.10.2021

После рецензирования 05.11.2021

Revised 05.11.2021

Принята 12.11.2021

Accepted 12.11.2021 